\title{
ARTIGO
}

\section{Equipamentos culturais, bibliotecas e profissionais da informação no Brasil: indicadores estaduais por volta de $2000^{1}$}

\author{
Cultural equipment, libraries and \\ information professionals in Brazil: \\ state indicators by the year 2000
}

Paulo de Martino JANNUZZI²

Mônica de Fátima LOUREIRO ${ }^{3}$

\section{R E S U M O}

O presente trabalho tem como objetivo principal identificar e analisar a distribuição da infra-estrutura de equipamentos e serviços voltados para a difusão cultural à população nos estados brasileiros, entendendo-se por isto o conjunto de bibliotecas públicas, museus, teatros, cinemas, emissoras de rádio, provedores de Internet e outros serviços levantados na Pesquisa de Informações Básicas Municipais de 1999, divulgada pelo Instituto Brasileiro de Geografia e Estatística em 2001. Apresenta-se também a distribuição dos profissionais envolvidos nessas atividades, tais como os profissionais da informação e do

\footnotetext{
${ }^{1}$ A elaboração deste trabal ho contou com contribuições valiosas de várias pessoas. Assim, agradecemos às mestrandas Giovana Rizzo, Sílvia Celeste Sávio e Lígia Ferrari Fuentes pela exploração de al gumas pesquisas e bases de dados apresentadas em seus seminários na disciplina Métodos Quantitativos em Ciência da Informação; ao mestrando Marcos Bueno, pela trabalhosa e competente preparação da base de microdados do Censo Demográfico 2000, à Marcela Arruda, mestranda da EN CE/IBGE, pelo processamento de algumas informações aqui apresentadas; à Profa. Maria de Fátima Tálamo, pela indicação da consulta ao Dicionário Crítico de Política Cultural, referência bibliográfica básica e fundamental para este trabalho. As interpretações, lacunas e outras imperfeições no uso do material empírico e bibliográfico usado são da responsabilidade exclusiva dos autores do presente texto.

2 Professor convidado, Programa de Pós-graduação em Ciência da Informação, Pontifícia Universidade Católica de Campinas. Praça Imaculada, 105, Vila Santa O dila, 13045-901, Campinas, SP, Brasil. E-mail: pjannuzzi@puc-campinas.edu.br

3 Bibliotecária. Mestranda em Ciência da Informação, Pontifícia Universidade Católica de Campinas, Bolsista Capes. E-mail: monicaeros@hotmail.com
} 
jornalismo, bem como escritores e professores, a partir de dados do Censo Demográfico de 2000. Em particular, discutem-se os indicadores de disponibilidade e oferta de serviços bibliotecários nos estados brasileiros, incluindo-se a relação dos mesmos com indicadores econômicos e sociais.

Palavras-chave: difusão cultural, bibliotecas públicas, profissionais da informação.

\title{
A B S T R A C T
}

\begin{abstract}
The present work has as its main objective to identify and to analyze the infrastructure's distribution of equipment and services intended for cultural dissemination among the population in Brazilian states, understanding as such the array of public libraries, museums, theaters, cinemas, radio broadcasting networks, Internet suppliers and other services, as gathered in the Pesquisa de Informações Básicas Municipais of 1999, published by the Instituto Brasileiro de Geografia e Estatística in 2001. This work also presents the distribution of professionals involved in these activities, such as the information and journalism professionals, writers and professors, according to the census data presented in the Censo Demográfico of 2000. In particular, it discusses the indicators of librarianship services' availability and demand in the Brazilian states, as well as the relationship they bear to economic and social indicators.
\end{abstract}

Key words: cultural diffusion, public libraries, information professionals.

\section{N T R O D U Ç Ã O}

O desenvolvimento acelerado das tecnologias de informática e telecomunicações, o surgimento de novas mídias para armazenamento de dados e o barateamento relativo desses equipamentos nos últimos 30 anos gerou em boa parte da comunidade de pesquisadores das Ciências Sociais e também na Ciência da Informação, um deslumbramento e uma crença voluntarista de que os antigos e conhecidos problemas de acesso à informação estariam prontamente resolvidos.

$\mathrm{Na}$ Sociedade do Conhecimento, Sociedade Cibernética ou Sociedade da Informação seria possível colocar à disposição da população, através de microcomputadores pessoais ou quiosques públicos, conteúdos e mais conteúdos de informação das mais variadas naturezas, fontes e aplicações. Pelo acesso virtual desse repertório multifacetado, o indivíduo tornar-se-ia um cidadão, pelas possibilidades de aprendizado educacional, de aprimoramento profissional, de conhecimento de seus direitos, de controle social dos gastos públicos, de contato direto via mail com seus representantes eleitos. Disso tudo decorreria uma sociedade mais justa e democrática, enfim um ingresso indolor e acelerado no Primeiro Mundo (GERMAN, 2000; SCHWARTZ, 2000).

Emblemático nesse sentido é o Livro Verde da Sociedade da Informação no Brasil (TAKAHASHI, 2000), onde, em suas 195 páginas entroniza o acesso digital e as novas tecnologias como a solução estratégica para nosso subdesenvolvimento social, econômico e cultural:

A sociedade da informação não é um modismo. Representa uma profunda mudança na organi- 
zação da sociedade e da economia, havendo quem a considere um novo paradigma técnico-econômico. É um fenômeno global, com elevado potencial transformador das atividades sociais e econômicas, uma vez que a estrutura e a dinâmica dessas atividades inevitavelmente serão, em alguma medida, afetadas pela infra-estrutura de informações disponível (TAKAHASHI, 2000, p.5).

Nesta perspectiva só nos restaria engajar, com todas as forças e recursos, o "tecnologismo digital" como diretriz de ação nos vários campos da ação humana, uma vez que, na visão dos formuladores do Livro Verde

(...) a construção de uma sociedade da informação democrática no Brasil está visceralmente dependente do apoio à pesquisa em tecnologia de produção e comunicação de conteúdos e da criação de condições para a capacitação universal dos cidadãos para o uso das novas tecnologias. Depende também de que as instituições culturais públicas tenham plenas condições de uso das potencialidades das tecnologias relativas à produção, difusão e disponibilização de acesso de conteúdos veiculadores ou construtores de nossa identidade cultural (TAKAHASHI, 2000, p.61).

Em tal formulação, às bibliotecas restaria a função - estratégica - de garantir acesso público, gratuito e assistido à Internet ou quando muito, se constituiriam em centros virtuais de documentação, conectadas às bases de dados mundiais, com acervo eletrônico de livros clássicos e atuais, intermediando pedidos e ofertas de um mercado de periódicos online (CUNHA, 2000).
Os arquivos, bibliotecas, museus e centros de documentação cumprirão papel estratégico. Viabilizarão, para pessoas e comunidades não diretamente conectadas, o acesso público, gratuito e assistido aos conteúdos da Internet. Reproduzirão, na Internet, a função de operar coleções de conteúdos organizados segundo metodologias e padrões de seleção e qualidade (TAKAHASHI, 2000, p.65).

O aumento da desigualdade social, a explosão da violência, a cristalização do desemprego estrutural nesse mesmo período, nos países centrais inclusive, encarregou-se de mostrar a ingenuidade dessas análises apologéticas do tecnologismo digital como solução mágica para as distorções do Capitalismo "pós-industrial". Essa desilusão com as promessas das novas tecnologias chegou à pesquisa da Ciência da Informação ao final dos anos 90 , como o revelam a freqüência com que termos como Infoexclusão e Exclusão Digital passaram a ser enfocados nos textos acadêmicos.

Rocha (2000) caracteriza bem essa ambigüidade de sentidos que o novo paradigma desperta na comunidade de pesquisadores, ao contrapor o discurso voluntarista daqueles para quem a sociedade da informação seria uma comunidade voltada para o "compartilhamento de recursos e para o bem-estar social" ao de outros com uma posição mais crítica e sensata para quem

(...) a sociedade da informação corre o risco de se fechar em feudos, prevalecendo os interesses dos "barões da mídia", buscando grandes lucros e acentuando as desigualdades. Alerta para o risco de limitação dos direitos de informação do cidadão e julga que a globa- 
lização, a privatização dos meios de telecomunicações e o direito de propriedade intelectual estão a serviço de grupos poderosos (ROCHA, 2000, p.42).

No mesmo sentido, fazendo um paralelo entre a revolução industrial e a informacional, Carvalho e Kaniski (2000, p.38), lembram que ambas "têm contribuído para a maximização do trabalho e da comunicação entre os homens, mas pouco alteraram as relações de poder existentes no interior desses processos". Ao que Baggio (2000, p.16) acrescenta: "se esse conhecimento acumulado não for compartilhado pela sociedade como um todo, corremos o risco de ratificarmos o abismo que separa os ricos dos pobres".

Nesse quadro, temas clássicos e muito caros à área parecem estar merecendo releituras e revisões, resgatando discussões recorrentes e antigas. Uma dessas, que particularmente motiva a proposição deste trabalho, é a do acesso limitado às fontes e serviços de informação e à cultura. Como mostra Suaiden (2000), muito antes da exclusão digital, a sociedade brasileira já vem convivendo com a dificuldade de acesso ao livro e à biblioteca pública ao longo de sua história. Em um passado não muito remoto, com uma elevada proporção de população analfabeta ou semi-alfabetizada, o livro era um bem não procurado, ou era objeto de decoração, em belas encadernações, em salas de visitas e salas de estar da classe média. Biblioteca pública era um templo, para os iluminados que professavam o culto às Letras, Artes e Ofícios.

[Nesse período] a preocupação predominante era a preservação do material bibliográfico, e muitas [bibliotecas] se negavam a fazer o empréstimo domiciliar com receio de o livro ser furtado, e assim o profissional teria de dar conta do material permanente. $\mathrm{O}$ livro não era somente associado a material permanente, como era também um símbolo de status intelectual do seu proprietário (SUAIDEN, 2000, p.54)

O Brasil cresceu, a população passou a ter maior acesso à escola; a indústria editorial e cultural apareceu e diversificou-se, mas o livro, o jornal, a biblioteca pública continuam aparentemente atingindo públicos potencialmente menores que os que se poderia inferir pelo tamanho do Produto Interno Bruto (PIB), PIB per capita ou Desenvolvimento Humano que o país exibe. As tiragens dos 3 maiores jornais do país, por exemplo, estão entre 300 e 500 mil exemplares diários, patamar alcançado por vários diários de países europeus com população muito inferior à brasileira, como o El Pais da Espanha, com uma tiragem diária de 557 mil para uma população de 39 milhões de pessoas, ou o Le Monde, com tiragem de $400 \mathrm{mil} /$ dia para uma população de 59 milhões de franceses (CIRCULAÇÃO..., 2001).

Acesso à cultura e à informação, plural, de diferentes naturezas, fontes e suportes convencionais ainda é, pois, uma das questões recorrentes nos estudos de Disseminação de Informação. É na perspectiva de contribuir para políticas, programas e atividades no campo do Acesso Cultural - nos termos definidos por Teixeira Coelho (1997) em seu Dicionário Crítico de Política Cultural, como a possibilidade de contato direto com uma unidade de produção, distribuição ou uso/consumo/troca de produtos culturais - que se propõe este artigo. Mais especificamente, trata-se aqui do acesso físico a equipamentos culturais específicos, isto é, da possibilidade de contato direto com "edificações destinadas a práticas culturais (teatros, cinemas, bibliotecas, centros de cultura, filmotecas, museus)" (TEIXEIRA COELHO, 1997, p.165), condição prévia para o que o autor chama de acesso intelectual ou apropriação efetiva do produto cultural. 
Assim, o objetivo deste trabalho é apresentar uma análise da distribuição, pelos estados brasileiros, da infra-estrutura física voltada à difusão cultural e/ou comunicação social à população - tais como bibliotecas, livrarias, teatros, museus, jornais, emissoras de rádio, TVs a cabo, provedores de Internet, vídeolocadoras, cinemas - bem como dos recursos humanos - profissionais da informação, jornalistas, escritores - envolvidos diretamente nestas atividades, na forma possibilitada pela Pesquisa de Informações Básicas Municipais (MUNIC) de 1999, publicada em 2001 pelo Instituto Brasileiro de Geografia e Estatística (IBGE) e pelo Censo Demográfico 2000.

O trabalho está dividido em três seções principais. As duas primeiras seções têm caráter mais descritivo, apresentando, primeiramente, indicadores acerca da disponibilidade de equipamentos culturais, públicos e privados, e em seguida, dados acerca da distribuição de profissionais em ocupações relacionadas. A terceira seção discute, mais especificamente, indicadores de disponibilidade e oferta de serviços bibliotecários nos estados brasileiros, e a relação dos mesmos com indicadores econômicos e sociais.

\section{A Infra-estrutura de equipamentos culturais}

Já adentrado o século XXI, em fase supostamente adiantada do processo de inserção na Sociedade da Informação - como querem os apologéticos do tecnologismo digital - não se dispõe no Brasil de um levantamento atualizado e exaustivo do conjunto de seus equipamentos e serviços de difusão cultural nos municípios brasileiros, nos moldes do que, ainda que de forma parcial, cobriu a Pesquisa Bibliotecas Brasileiras, realizada pelo IBGE no final da década de 1970, patrocinada pelo Instituto Nacional do Livro (PESQUISA BIBLIOTECAS..., 1980). Essa pesquisa, além de quantificar o número das bibliotecas existentes em 1976 - com 300 ou mais volumes em seu acervo - segundo as diferentes categorias - universitária, escolar, especializada - e a dependência administrativa - federal, estadual, municipal, particular - também investigou o espaço disponível, as características do serviço de controle do acervo, seu tamanho e diversidade (livros, folhetos, periódicos), pessoal alocado (bibliotecários, documentalistas, auxiliares), gastos com aquisição, pessoal e manutenção e disponibilidade de máquinas e equipamentos ${ }^{4}$. Enfim, tratou-se de um amplo diagnóstico do setor, não repetido posteriormente.

Dessa forma, na inexistência - ou pelo menos, na não publicização - de um registro censitário nacional da infra-estrutura de equipamentos e serviços de difusão cultural, uma das alternativas para se chegar a estimativas mais atualizadas sobre a disponibilidade de bibliotecas, museus, teatros é através da Pesquisa de Informações Básicas Municipais (MUNIC), realizada pelo IBGE junto às prefeituras dos mais de 5.500 municípios brasileiros. O primeiro levantamento da pesquisa foi a campo em 1999, e seus resultados vieram a público em 2001 contemplando um conjunto amplo de informações municipais (240 variáveis), desde aspectos sobre a estrutura administrativa, nível de institucionalização do planejamento urbano, participação da sociedade em conselhos aos temas que, particularmente interessam a este trabalho, sobre a disponibilidade de diversos equipamentos, públicos e privados, de difusão

\footnotetext{
${ }^{4}$ À época, 1976, tal pesquisa apontou a existência de 14.884 bibliotecas, das quais 9.019 escolares e 3.257 públicas (dentre as quais 2.543 municipais). 0 acervo dispunha de 48,5 milhões de exemplares de livros, correspondentes a 27,6 milhões de títulos, e 1,2 milhão de títulos de periódicos. No conjunto das bibliotecas pesquisadas trabal havam 30.321 pessoas, das quais 4.271 bibliotecários ou documentalistas com nível superior (nas bibliotecas públicas eram apenas 760 bibliotecários e documentalistas) (PESQUISA BIBLIOTECAS..., 1980).
} 
cultural, comunicação social, de comércio e serviços $^{5}$.

Para as finalidades deste trabalho selecionou-se, dentre os quesitos levantados, aqueles referentes a disponibilidade de bibliotecas públicas, livrarias, vídeolocadoras, provedores de Internet, repetidoras de TV Educativa, TVs a cabo, emissoras de rádio $\mathrm{AM}$, museus, sedes de jornais diários, cinemas e teatros (Quadro 1), juntamente com o conceito operacional adotado na pesquisa. Vale observar que, no tocante à recepção de sinal de TV, considerou-se para análise apenas a proveniente da Rede Cultura ou Educativa, já que o sinal da TV Globo e de outras grandes redes estão praticamente universalizados no território nacional.

Naturalmente, tratando-se de uma pesquisa com múltiplos propósitos e não específica para o mapeamento da oferta e produção cultural no país, as informações levantadas acerca dos equipamentos e serviços, acima relacionados, são bastante limitadas, referindo-se, em geral, à existência ou não do equipamento/serviço no município ou, em alguns casos, como o das bibliotecas públicas, o número de unidades existentes. Acredita-se, contudo que, ainda que com tais limitações, os dados disponíveis cumprem a finalidade pretendida neste trabalho de ilustrar o quadro de desigualdade e restrição de acesso a repertórios plurais de informação e cultura pelo país, em uma perspectiva próxima da discutida por Alkmin (2002).

Pelos resultados da MUNIC, dos 5.507 municípios então existentes no país em 1999, $4.200(76 \%$ deles $)$ tinham pelo menos uma biblioteca pública (Tabela 1). Embora não haja elementos na pesquisa que permitam caracterizar a qualidade das instalações, o tamanho e diversidade do acervo ou mesmo a acessibilidade da população à biblioteca, no contexto da gravidade dos problemas na questão educacional no país (elevado analfabetismo funcional, baixa performance escolar, baixo gasto público em educação e cultura, etc.), a existência de um equipamento reconhecido como biblioteca, pela parcela majoritária de prefeituras, pode representar algum alento para implementação de políticas públicas no campo da leitura, difusão cultural, prestação de serviços informacionais e mesmo inclusão digital. Como ver-se-à mais à frente, nenhum outro equipamento ou serviço dentre os levantados pela MUNIC está tão presente nos municípios brasileiros como as bibliotecas públicas ${ }^{6}$.

Como era de se esperar, em função do nível de desenvolvimento econômico, gasto público em educação e cultura e do perfil educacional da população, é mais frequente encontrar bibliotecas nos municípios dos estados do Sudeste e Sul que em outras regiões ${ }^{7}$. Nos estados do Centro-Oeste, as cifras são também mais elevadas ou próximas da média nacional, chegando, no caso do Mato Grosso do Sul, a surpreendente proporção de $90 \%$ de municípios com pelo menos uma biblioteca. Com relação ao Distrito Federal, os resultados da pesquisa devem ser entendidos com cautela, já que nessa unidade federada reconhece-se, oficialmente, apenas Brasília como município, em que pese o porte populacional das cidades-satélites e a distância das mesmas do Plano Piloto.

\footnotetext{
5 Vale observar que em 2001 foi realizada nova coleta de dados junto às prefeituras, cujos resultados vieram a publico em meados de 2003. U ma análise prel iminar dos resultados referentes às áreas de interesse desse trabal ho acabou por demonstrar que as mudanças de questionário e conceitos requerem, contudo, estudos mais aprofundados para sua efetiva utilização.

6 Vale observar que esses resultados dizem respeito à existência de Bibliotecas Públicas, não incluindo pois as bibliotecas escolares, certamente muito mais numerosas no país.

${ }^{7}$ No apêndice traz-se al gumas estatísticas demográficas, sociais e econômicas para os estados brasileiros, que além de servirem ao cálculo dos indicadores nas tabelas do texto principal, prestam-se como referência adicional nas interpretações dos resultados aqui apresentados.
} 
Quadro 1. Equipamentos e serviços de difusão cultural, comércio e serviços levantados pela MUNIC em 1999.

\begin{tabular}{|c|c|}
\hline Equipamento/Serviço & Definição \\
\hline Bibliotecas Públicas & $\begin{array}{l}\text { São todas aquelas que são abertas à freqüência do público em } \\
\text { geral, sejam elas mantidas por instituições governamentais ou } \\
\text { não. }\end{array}$ \\
\hline Cinemas & $\begin{array}{l}\text { Estabelecimentos cuja finalidade é a projeção de filmes, situa- } \\
\text { dos no município. }\end{array}$ \\
\hline Emissoras de Rádio AM & $\begin{array}{l}\text { São aquelas que geram e transmitem programação radiofônica } \\
\text { a partir do município. }\end{array}$ \\
\hline Jornais diários & Jornais diários com pauta específica do município. \\
\hline Livrarias & $\begin{array}{l}\text { Estabelecimento que comercializa livros e outros produtos } \\
\text { culturais, escolares, para - escolares, eventualmente artigos } \\
\text { de papelaria e informática. }\end{array}$ \\
\hline Museus & $\begin{array}{l}\text { É uma instituição permanente, sem finalidade lucrativa, a serviço } \\
\text { da sociedade e de seu desenvolvimento, aberta ao público, } \\
\text { voltada à pesquisa dos testemunhos materiais do homem e do } \\
\text { seu entorno, que os adquire, conserva, comunica e, } \\
\text { notadamente, expõe, visando estudos, educação e lazer. }\end{array}$ \\
\hline Provedores de Internet & Empresa prestadora de serviço de acesso à Internet. \\
\hline Recepção de sinal de TV Educativa/Cultura & $\begin{array}{l}\text { Identificação de recepção da sintonia de TV Educativa ou } \\
\text { Cultura no município. }\end{array}$ \\
\hline Teatros ou Casas de Espetáculos & $\begin{array}{l}\text { São estabelecimentos ou edificações cuja finalidade é a } \\
\text { apresentação de arte dramática, música, dança, etc. }\end{array}$ \\
\hline TV a Cabo & $\begin{array}{l}\text { Existência de cabeamento para fins de distribuição de } \\
\text { programação televisiva no município. }\end{array}$ \\
\hline Vídeo Locadora & $\begin{array}{l}\text { Estabelecimentos que oferecem o serviço de aluguel de fitas de } \\
\text { vídeo. }\end{array}$ \\
\hline
\end{tabular}

Fonte: Pesquisa... (2001).

Se é fato que parcelas significativas de municípios de estados do Norte e Nordeste não dispõem de biblioteca pública - como aqueles de menor porte, mais inscrustados na Amazônia ou Sertão Nordestino, como sugerem os resultados para Acre e Piauí (onde menos da metade dos municípios dispõe de uma biblioteca) - é preciso ressaltar que, mesmo em um quadro de carência de recursos econômicos e fundos públicos, há situações bastante alvissareiras. No Rio Grande do Norte, por exemplo, a pesquisa aponta que existem bibliotecas públicas em 151 dos 166 municípios existentes (91\% dos mesmos). Cifras comparativamente elevadas também foram identificadas para Pernambuco e Tocantins, seguidos de Ceará e Pará.

Como revela a pesquisa, a disponibilidade de museus e teatros é mais uma exceção do que regra nos municípios brasileiros. Apenas 854 municípios (15,5\%) dispõem de museu e um número ainda menor - 753 municípios (14,0\%) - dispõe de teatro, desnudando o quadro histórico de baixo investimento público no setor. De fato, o gasto médio per capita dos governos estaduais em Educação e Cultura foi, em 2000, de 165 reais por habitante. 
Considerando os recursos necessários à operação das escolas públicas - despesas também cobertas por esta rubrica do orçamento - a verba para instalação e manutenção de museus e teatros acaba sendo residual. Nesse contexto, é nos municípios dos estados do Rio de Janeiro e São Paulo que se pode encontrar, com maior regularidade, esses equipamentos culturais pela maior disponibilidade de recursos municipais próprios, verbas estaduais e federais, maior quantidade e diversidade do patrimônio histórico e talvez maior participação da iniciativa privada e da sociedade civil nestas atividades. Em 34,0\% dos municípios fluminenses há pelo menos um museu; em $41,0 \%$ há pelo menos um teatro.

Um cenário um pouco melhor, mas ainda insatisfatório, é o relativo à existência de livrarias, presentes em cerca de um terço dos municípios

Tabela 1. Municípios com pelo menos uma unidade de equipamento ou serviço de difusão cultural segundo Unidades da Federação. Brasil, 1999.

\begin{tabular}{|c|c|c|c|c|c|c|c|c|}
\hline \multirow{2}{*}{ Unidades da Federação } & \multicolumn{2}{|c|}{ Bibliotecas Públicas } & \multicolumn{2}{|c|}{ Museus } & \multicolumn{2}{|c|}{ Teatros } & \multicolumn{2}{|c|}{ Livrarias } \\
\hline & $\mathrm{n}$ & $\%$ & $\mathrm{n}$ & $\%$ & $\mathrm{n}$ & $\%$ & $\mathrm{n}$ & $\%$ \\
\hline Rondônia & 34 & 65,3 & 6 & 11,5 & 5 & 9,6 & 24 & 46,1 \\
\hline Acre & 10 & 45,4 & 2 & 9,0 & 4 & 18,1 & 4 & 18,1 \\
\hline Amazonas & 44 & 70,9 & 4 & 6,4 & 13 & 20,9 & 10 & 16,1 \\
\hline Roraima & 5 & 33,3 & 1 & 6,6 & 4 & 26,6 & 5 & 33,3 \\
\hline Pará & 109 & 76,2 & 10 & 6,9 & 15 & 10,4 & 51 & 35,6 \\
\hline Amapá & 8 & 50,0 & 1 & 6,2 & 1 & 6,2 & 4 & 25,0 \\
\hline Tocantins & 111 & 79,8 & 6 & 4,3 & 4 & 2,8 & 11 & 7,9 \\
\hline Maranhão & 113 & 52,0 & 6 & 2,7 & 8 & 3,6 & 47 & 21,6 \\
\hline Piauí & 99 & 44,7 & 12 & 5,4 & 10 & 4,5 & 18 & 8,1 \\
\hline Ceará & 151 & 82,0 & 29 & 15,7 & 31 & 16,8 & 64 & 34,7 \\
\hline Rio Grande do Norte & 151 & 90,9 & 14 & 8,4 & 9 & 5,4 & 36 & 21,6 \\
\hline Paraíba & 148 & 66,3 & 18 & 8,0 & 34 & 15,2 & 29 & 13,0 \\
\hline Pernambuco & 158 & 85,4 & 32 & 17,2 & 40 & 21,6 & 50 & 27,0 \\
\hline Alagoas & 65 & 64,3 & 10 & 9,9 & 10 & 9,9 & 25 & 24,7 \\
\hline Sergipe & 46 & 61,3 & 7 & 9,3 & 7 & 9,3 & 20 & 26,6 \\
\hline Bahia & 282 & 67,9 & 30 & 7,2 & 56 & 13,4 & 150 & 36,1 \\
\hline Minas Gerais & 708 & 83,0 & 104 & 12,1 & 104 & 12,1 & 190 & 22,2 \\
\hline Espírito Santo & 71 & 92,2 & 14 & 18,1 & 14 & 18,1 & 28 & 36,3 \\
\hline Rio de Janeiro & 77 & 84,6 & 31 & 34,0 & 37 & 40,6 & 41 & 45,0 \\
\hline São Paulo & 532 & 82,4 & 164 & 25,4 & 145 & 22,4 & 274 & 42,4 \\
\hline Paraná & 325 & 81,4 & 63 & 15,7 & 66 & 16,5 & 233 & 58,3 \\
\hline Santa Catarina & 234 & 79,8 & 86 & 29,3 & 31 & 10,5 & 152 & 51,8 \\
\hline Rio Grande do Sul & 366 & 78,3 & 165 & 35,3 & 70 & 14,9 & 289 & 61,8 \\
\hline Mato Grosso do Sul & 69 & 89,6 & 10 & 12,9 & 6 & 7,7 & 53 & 68,8 \\
\hline Mato Grosso & 95 & 75,3 & 7 & 5,5 & 10 & 7,9 & 65 & 51,5 \\
\hline Goiás & 188 & 77,6 & 21 & 8,6 & 18 & 7,4 & 73 & 30,1 \\
\hline Distrito Federal & 1 & 100,0 & 1 & 100,0 & 1 & 100,0 & 1 & 100,0 \\
\hline Total & 4.200 & 76,3 & 854 & 15,5 & 753 & 13,7 & 1.947 & 35,4 \\
\hline
\end{tabular}

Fonte: Pesquisa... (2001). 
brasileiros. Tal resultado decorre, pela análise de Siciliano (2003), de uma série de fatores obstaculizantes à expansão do setor no país, relacionados à baixa demanda por livros e à capacidade financeira e gerencial de eventuais interessados no setor. De fato, embora a indústria editorial brasileira esteja crescendo, as estatísticas de produção são tímidas quando comparadas com países mais desenvolvidos ou vizinhos aqui na América Latina: dados da Organização das Nações Unidas para a Educação, a Ciência e a Cultura (Unesco) ${ }^{8}$ mostram que o Brasil publicava no final dos anos 1990 cerca de 20 a 22 mil títulos de livros por ano, metade do verificado na França, com uma população de 59 milhões de pessoas, ou apenas o dobro do verificado na Argentina, que tem uma população de cerca de 37 milhões, correspondente a menos de um quarto da brasileira.

Como observa o autor, em que pesem os avanços nas taxas de cobertura escolar, o nível de escolaridade da população brasileira ainda é baixo (31\% de pessoas, com 10 anos ou mais, com até 3 anos de estudo em 2000), sobretudo nas pequenas cidades, localizadas no Norte e Nordeste. Tal fato, associado ao baixo nível de rendimento médio das famílias, torna o livro um objeto de consumo pouco acessível. O levantamento "Retrato da Leitura no Brasil", realizado pela Câmara Brasileira do Livro no começo de 2001 , revelou que apenas $20 \%$ das 86 milhões de pessoas alfabetizadas com mais de 14 anos residentes no país havia comprado pelo menos um livro no ano anterior (CÂMARA..., 2001) ${ }^{9}$. Entre os mais pobres (classe D/E segundo critérios de mercado) apenas 10\% havia adquirido ao menos um livro. Mesmo entre aqueles com nível superior o consumo de livro não era a regra: pouco mais da metade (55\%) havia comprado ao menos um livro em 2000. A pesquisa identificou ainda que apenas $14 \%$ das pessoas (12 milhões) estavam lendo algum livro por ocasião da entrevista e que, desses leitores correntes, mais da metade estava lendo a Bíblia, livros religiosos ou de auto-ajuda.

Baixo consumo implica em menores tiragens e portanto menor ganho de escala no processo produtivo, fazendo com que o livro acabe ficando caro para produzir, distribuir ou comercializar. Ademais, montar uma livraria requer um investimento inicial alto, já que a venda por consignação não é uma política praticada de forma generalizada pelas editoras. Vale observar que, lidar com livros - ainda que os de auto-ajuda, místicos, os de maior consumo - requer um nível de qualificação técnica adequado. Assim, para o pequeno comerciante ou empreendedor-que poderia expandir a infra-estrutura de distribuição nas pequenas cidades e no Norte e Nordeste - as livrarias acabam perdendo atratividade frente a outras alternativas de investimento e negócios. A presença de livrarias em apenas 18 dos 99 municípios do Piauí, ou em 11 dos 111 do Tocantins, é sintomática nesse sentido. De fato, pela pesquisa Retrato da Leitura acima mencionada mais da metade das compras de livro no país efetua-se nas capitais e grandes cidades. Assim, para boa parte dos brasileiros, acesso ao livro, só na biblioteca, quando existente.

Com relação aos equipamentos e serviços de comunicação social (Tabela 2), os jornais diários locais contituem-se no meio informacional mais comum nos municípios brasileiros. Em 4.011 dos 5.507 municípios então existentes em 1999 havia pelo menos um jornal local diário, resultado, à primeira vista, um tanto surpreendente em se tratando do tipo de mídia e sua periodicidade. Contudo, uma reflexão um pouco mais balizada, revela que a cifra de $73 \%$ de municípios com jornal diário só pode ser entendida se se considerar a necessidade de publicização oficial das decisões do executivo e legislativo municipais - Diário Oficial do Município - assim como também o papel desse

\footnotetext{
${ }^{8}$ Vide www.uis.unesco.org, estatísticas de comunicação e cultura.

${ }^{9}$ A pesquisa levantou informações junto a cerca de 5.500 domicílios no país, em janeiro de 2001.
} 
veículo nas disputas locais de hegemonia política. A importância do jornal local como instrumento de propaganda e formação de opinião pública, nos pequenos municípios, ganha evidência adicional quando se tomam os resultados ainda mais surpreendentes no Ceará e Rio Grande do Norte (mais de $90 \%$ dos municípios com jornal diário), estados em que as disputas políticas locais aparecem noticiadas na grande mídia, menos pelo que trazem de novo e moderno e mais pelo que reproduzem de práticas arcaicas de coronelismo (é o "coronelismo informacional", antes proprietário das terras, hoje donos e concessionários dos diversos meios de comunicação nos municípios brasileiros).

Tabela 2. Municípios com pelo menos uma unidade de equipamento ou serviço de difusão cultural segundo Unidades da Federação. Brasil, 1999.

\begin{tabular}{|c|c|c|c|c|c|c|c|c|c|c|c|c|c|c|}
\hline \multirow[t]{2}{*}{$\begin{array}{l}\text { Unidades da } \\
\text { Federação }\end{array}$} & \multicolumn{2}{|c|}{$\begin{array}{l}\text { Jornais } \\
\text { Diários }\end{array}$} & \multicolumn{2}{|c|}{ Cinemas } & \multicolumn{2}{|c|}{$\begin{array}{c}\text { Vídeo } \\
\text { Locadoras }\end{array}$} & \multicolumn{2}{|c|}{$\begin{array}{c}\text { Emissoras } \\
\text { de Rádio } \\
\text { AM }\end{array}$} & \multicolumn{2}{|c|}{$\begin{array}{c}\text { Recepção de } \\
\text { sinal de TV } \\
\text { Educativa/ } \\
\text { Cultura }\end{array}$} & \multicolumn{2}{|c|}{$\begin{array}{c}\text { TVs } \\
\text { a Cabo }\end{array}$} & \multicolumn{2}{|c|}{$\begin{array}{l}\text { Provedores } \\
\text { de Internet }\end{array}$} \\
\hline & $\mathrm{n}$ & $\%$ & $\mathrm{n}$ & $\%$ & $\mathrm{n}$ & $\%$ & $\mathrm{n}$ & $\%$ & $\mathrm{n}$ & $\%$ & $\mathrm{n}$ & $\%$ & $\mathrm{n}$ & $\%$ \\
\hline Rondônia & 37 & 71,1 & 3 & 5,7 & 29 & 55,7 & 9 & 17,3 & 14 & 26,9 & 7 & 13,4 & 11 & 21,1 \\
\hline Acre & 8 & 36,3 & 1 & 4,5 & 9 & 40,9 & 7 & 31,8 & 1 & 4,5 & 0 & - & 2 & 9,0 \\
\hline Amazonas & 19 & 30,6 & 4 & 6,4 & 30 & 48,3 & 22 & 35,5 & 12 & 19,4 & 12 & 19,3 & 3 & 4,8 \\
\hline Roraima & 8 & 53,3 & 1 & 6,6 & 6 & 40,0 & 4 & 26,7 & 2 & 13,3 & 2 & 13,3 & 3 & 20,0 \\
\hline Pará & 51 & 35,6 & 8 & 5,5 & 91 & 63,6 & 24 & 16,8 & 31 & 21,7 & 8 & 5,5 & 19 & 13,2 \\
\hline Amapá & 4 & 25,0 & 1 & 6,2 & 9 & 56,2 & 1 & 6,3 & 5 & 31,3 & 0 & - & 2 & 12,5 \\
\hline Tocantins & 64 & 46,0 & 2 & 1,4 & 26 & 18,7 & 8 & 5,8 & 20 & 14,4 & 4 & 2,8 & 6 & 4,3 \\
\hline Maranhão & 67 & 30,8 & 7 & 3,2 & 68 & 31,3 & 36 & 16,6 & 40 & 18,4 & 7 & 3,2 & 10 & 4,6 \\
\hline Piauí & 100 & 45,2 & 3 & 1,3 & 45 & 20,3 & 34 & 15,4 & 18 & 8,1 & 0 & - & 4 & 1,8 \\
\hline Ceará & 169 & 91,8 & 8 & 4,3 & 121 & 65,7 & 51 & 27,7 & 139 & 75,5 & 12 & 6,5 & 10 & 5,4 \\
\hline Rio Grande do Norte & 149 & 89,7 & 4 & 2,4 & 69 & 41,5 & 26 & 15,7 & 31 & 18,7 & 4 & 2,4 & 11 & 6,6 \\
\hline Paraíba & 117 & 52,4 & 8 & 3,5 & 86 & 38,5 & 22 & 9,9 & 9 & 4,0 & 1 & 0,4 & 6 & 2,6 \\
\hline Pernambuco & 153 & 82,7 & 22 & 11,8 & 148 & 80,0 & 27 & 14,6 & 64 & 34,6 & 12 & 6,4 & 20 & 10,8 \\
\hline Alagoas & 75 & 74,2 & 3 & 2,9 & 57 & 56,4 & 11 & 10,9 & 10 & 9,9 & 2 & 1,9 & 2 & 1,9 \\
\hline Sergipe & 34 & 45,3 & 2 & 2,6 & 52 & 69,3 & 9 & 12,0 & 35 & 46,7 & 5 & 6,6 & 7 & 9,3 \\
\hline Bahia & 247 & 59,5 & 17 & 4,0 & 236 & 56,8 & 62 & 14,9 & 194 & 46,7 & 16 & 3,8 & 42 & 10,1 \\
\hline Minas Gerais & 532 & 62,3 & 56 & 6,5 & 565 & 66,2 & 133 & 15,6 & 430 & 50,4 & 51 & 5,9 & 124 & 14,5 \\
\hline Espírito Santo & 72 & 93,5 & 6 & 7,7 & 74 & 96,1 & 10 & 13,0 & 21 & 27,3 & 5 & 6,4 & 18 & 23,3 \\
\hline Rio de Janeiro & 82 & 90,1 & 19 & 20,8 & 89 & 97,8 & 35 & 38,5 & 57 & 62,6 & 20 & 21,9 & 30 & 32,9 \\
\hline São Paulo & 559 & 86,6 & 111 & 17,2 & 544 & 84,3 & 167 & 25,9 & 562 & 87,1 & 74 & 11,4 & 194 & 30,0 \\
\hline Paraná & 362 & 90,7 & 24 & 6,0 & 311 & 77,9 & 112 & 28,1 & 190 & 47,6 & 38 & 9,5 & 90 & 22,5 \\
\hline Santa Catarina & 275 & 93,8 & 25 & 8,5 & 212 & 72,3 & 73 & 24,9 & 81 & 27,6 & 20 & 6,8 & 65 & 22,1 \\
\hline Rio Grande do Sul & 447 & 95,7 & 45 & 9,6 & 340 & 72,8 & 132 & 28,3 & 206 & 44,1 & 35 & 7,4 & 88 & 18,8 \\
\hline Mato Grosso do Sul & 72 & 93,5 & 6 & 7,7 & 65 & 84,4 & 27 & 35,1 & 17 & 22,1 & 5 & 6,4 & 21 & 27,2 \\
\hline Mato Grosso & 89 & 70,6 & 2 & 1,5 & 89 & 70,6 & 30 & 23,8 & 17 & 13,5 & 5 & 3,9 & 24 & 19,0 \\
\hline Goiás & 218 & 90,0 & 10 & 4,1 & 146 & 60,3 & 38 & 15,7 & 134 & 55,4 & 24 & 9,9 & 32 & 13,2 \\
\hline Distrito Federal & 1 & 100,0 & 1 & 100,0 & 1 & 100,0 & 1 & 100,0 & 1 & 100,0 & 1 & 100,0 & 1 & 100,0 \\
\hline Total & 4.011 & 72,8 & 399 & 7,3 & 3.518 & 63,9 & 1.111 & 20,2 & 2.341 & 42,5 & 370 & 6,7 & 845 & 15,3 \\
\hline
\end{tabular}

Fonte: Pesquisa... (2001). 
Se, em 1999, era preciso percorrer em média 3 cidades para se encontrar uma livraria, melhor sorte tinha aquele que procurava uma vídeo locadora: em 2 das 3 cidades ele provavelmente encontraria um local para retirar uma fita de videocassete. Nos municípios dos Estados do Rio de Janeiro, Espírito Santo, São Paulo, Mato Grosso do Sul e naturalmente no Distrito Federal, as chances eram até maiores. Mais precisamente, em $64,0 \%$ dos municípios brasileiros, em 1999, podia-se encontrar uma vídeo locadora, reflexo da disseminação da posse da TV em cores e deste bem de consumo durável, o videocassete, na década de 1990. Dados dos últimos Censos Demográficos mostram que, em 1991, 52,7\% dos domicílios particulares permanentes, urbanos, no país dispunham de TV em cores; em 2000, já eram $92,2 \%$ dos domicílios urbanos com TV e 40,8\% com videocassete ${ }^{10}$. O barateamento relativo dos produtos, associado à conjuntura econômica favorável entre 1994 e 1996, com elevação da renda média familiar, queda das taxas de juros e flexibilização das políticas de crédito das lojas de varejo, além da emergência do segmento de produtos usados, criaram as condições propícias à aquisição de bens duráveis no período (PESQUISA DE CONDIÇÕES..., 1998). A baixa penetração de salas de cinema (presentes em 399 municípios) e da TV a cabo (370) pelo território nacional - com exceção dos municípios situados no Centro-Sul - é outro fator que favorece a expansão das vídeo locadoras ${ }^{11}$.

Embora seja muito difícil encontrar um município que não capte a freqüência dos meios de comunicação de massa sediados nas maiores cidades e capitais, em especial nos estados de São Paulo e Rio de Janeiro, em apenas $20 \%$ dos municípios há uma emissora de rádio $\mathrm{AM}$ e em menos da metade $(43 \%$, mais precisamente) deles recebe-se o sinal de TV
Educativa ou Cultura. Frente a essas cifras, é surpreendente constatar que empresas provedoras de Internet estejam presentes em 15\% dos municípios. Se no caso da comunicação radiofônica - ou mesmo no caso de provedores - não se esperava ou espera alcançar a totalidade dos municípios, em função do nível de investimento e escala geográfica de viabilidade econômica do negócio, com respeito à recepção do sinal de TVs públicas, o quadro apontado é certamente insatisfatório, dado o papel que esse tipo de veículo pode desempenhar nesse contexto descrito de inexistência ou baixa disponibilidade de equipamentos culturais. Mesmo em estados mais ricos, como Rio de Janeiro e Minas Gerais, a cobertura espacial da TV Educativa/Cultura deixa a desejar. Será que parte dos recursos do Fundo Nacional de Telecomunicações ou do programa da Sociedade da Informação não poderia ser usada para "plugar" a totalidade dos municípios nessa rede de difusão cultural?

\section{Os recursos humanos da difusão cultural}

O levantamento quantitativo, acerca de pessoal alocado em atividades ocupacionais específicas, tem sido um problema recorrente no Brasil. Diferentes pesquisas, cadastros ou bancos de dados, pertencentes ao IBGE, Ministérios ou Conselhos de Classe (Conselhos Regionais de Biblioteconomia, etc.) fornecem números diferentes de profissionais, mesmo quando - em tese - referem-se aos mesmos grupos ocupacionais. Isso torna as comparações internacionais ainda mais difíceis, como revelam, por exemplo, as estimativas de pessoal alocado em Pesquisa e Desenvolvimento veiculadas pela Unesco.

Um passo importante na superação desses problemas foi a proposição da nova

\footnotetext{
10 Dados obtidos através do SIDRA em www.ibge.gov.br. Em 2000, dos 37,4 milhões de domicílios particulares permanentes situados nas zonas urbanas, 34,4 milhões dispunham de TV (em cores ou PB) e 15,2 milhões tinham videocassete.

${ }^{11}$ Além disso, a rentabilidade ou o "giro" do negócio é certamente maior nas vídeo locadoras do que nas livrarias.
} 
Classificação Brasileira de Ocupações (CBO) de 2002, na medida em que permite uma melhor caracterização dos ofícios e atividades da população ocupada, organizada em cerca de 600 grupos ocupacionais. Essa classificação resulta de um amplo trabalho realizado desde meados dos anos 1990 de reorganização e compatibilização das estruturas de classificação das ocupações anteriormente usadas pelo Ministério do
Trabalho (CLASSIFICAÇÃO BRASILEIRA..., 1994) e a empregada pelo IBGE em suas pesquisas domiciliares, tendo como referência a Classificação Internacional Uniforme de Ocupações de 1988. A CBO 2002 estrutura as ocupações segundo uma lógica hierárquico-piramidal, na qual as 2.422 ocupações (e seus 7.258 títulos ocupacionais sinônimos) são agrupados em 596 famílias ocupacionais ${ }^{12}$. As famílias

Quadro 2. Famílias ocupacionais selecionadas da Classificação Brasileira de Ocupações (CBO) 2002.

\section{Família 2611: Profissionais do jornalismo}

Títulos ocupacionais: Arquivista pesquisador (jornalismo), assessor de imprensa, diretor de redação, editor, jornalista, produtor de texto, repórter Rádio/TV, revisor.

Descrição: recolhem, redigem, registram através de imagens e de sons, interpretam e organizam informações e notícias a serem difundidas, expondo, analisando e comentando os acontecimentos. Fazem seleção, revisão e preparo definitivo das matérias jornalísticas a serem divulgadas em jornais, revistas, televisão, rádio, Internet, assessorias de imprensa e quaisquer outros meios de comunicação com o público.

\section{Família 2612: Profissionais da informação}

Títulos ocupacionais: Bibliotecário, biblioteconomista, cientista de informação, documentalista, analista de informações (pesquisador de informações de rede), pesquisador de informações de rede.

Descrição: disponibilizam informação em qualquer suporte; gerenciam unidades como bibliotecas, centros de documentação, centros de informação e correlatos, além de redes e sistemas de informação. Tratam tecnicamente e desenvolvem recursos informacionais; disseminam informação com o objetivo de facilitar o acesso e geração do conhecimento; desenvolvem estudos e pesquisas; realizam difusão cultural; desenvolvem ações educativas. Podem prestar serviços de assessoria e consultoria.

\section{Família 2613: Arquivistas e museólogos}

Títulos ocupacionais: Arquivista, administrador de arquivos, museólogo, auxiliar de museus.

Descrição: organizam documentação de arquivos institucionais e pessoais, criam projetos de museus e exposições, organizam acervos museológicos públicos e privados. Dão acesso à informação, conservam acervos. Preparam ações educativas ou culturais, planejam e realizam atividades técnico-administrativas, orientam implantação das atividades técnicas. Participam da política de criação e implantação de museus e instituições arquivísticas.

\section{Família 2615: Profissionais da escrita}

Títulos ocupacionais: Autor-roteirista, adaptador de obras, critico literário e de artes, escritor de ficção e de não-ficção, poeta, redator de textos técnicos.

Descrição: escrevem textos literários para publicação, representação e outras formas de veiculação e para tanto criam projetos literários, pesquisando temas, elaborando esquemas preliminares. Podem buscar publicação ou encenação da obra literária bem como sua divulgação.

Fonte: Classificação Brasileira... (2002).

12 Estas famílias ocupacionais são agregadas em 192 subgrupos, que por sua vez se classificam em 47 subgrupos principais, reunidos, por fim, em 10 grandes grupos de ocupações. Vale observar que essas famílias passaram por algumas adaptações para uso nas pesquisas domiciliares do IBGE, como no caso do Censo 2000. 
reúnem pois ocupações que compartilham semeIhanças com relação à natureza da atividade laboral exercida e às qualificações exigidas (CLASSIFICAÇÃO BRASILEIRA..., 2002).

Dentre as famílias ocupacionais registradas na CBO 2002, as ocupações de interesse a este trabalho, correspondem, àquelas exercidas em geral por pessoas com formação superior e voltadas aos processos de disseminação de informação e difusão cultural. Mais especificamente, selecionou-se as famílias de Profissionais do Jornalismo (código 2611), Profissionais da Informação (cod. 2612), Arquivistas e museólogos (cod. 2613) e Profissionais da Escrita (cod. 2615) (Quadro 2).Para identificar o total de profissionais alocados nessas famílias ocupacionais, a fonte de dados mais adequada é o Censo Demográfico 2000. Através do questionário da amostra do Censo, o IBGE coletou uma série de informações demográficas, sociais e econômicas dos indivíduos, entre elas a ocupação exercida, classificada posteriormente dentro das categorias da CBO 2002. Com base na experiência de trabalho anterior com os Censos de 1980 e 1991 (JANNUZZI; MATTOS, 2001), por sua representatividade nacional e tamanho, a amostra do Censo permite desagregar, com nível de erro amostral satisfatório, boa parte dos grupos ocupacionais levantados.

Outras fontes disponíveis para tal levantamento, como a Relação Anual de Informações Sociais do Ministério do Trabalho, teria vantagem de, em tese, ter a informação sobre alocação ocupacional mais precisa, na medida em que o informante é a empresa. Ocorre que tal fonte de dados só cobre o segmento formal do mercado de trabalho, o que poderia trazer distorções importantes na comparabilidade das famílias ocupacionais elencadas (JANNUZZI, 2001). Usar dados de Conselhos de Classe só permitiria quantificar os segmentos em que tais conselhos existem e gozam de maior representatividade.
Assim, em uma perspectiva pragmática, o Censo Demográfico 2000 é uma escolha bastante defensável.

Pelo Censo 2000, havia no Brasil cerca de 33,7 mil pessoas ocupadas como jornalistas, repórteres, editores e outros títulos ocupacionais característicos dos Profissionais do Jornalismo, representando uma relação de 20 profissionais para cada 100 mil habitantes (Tabela 3). O Censo apontou também a existência de 32,5 mil Profissionais da Informação - entre biblioteconomistas, documentalistas, cientistas da informação - e 15,5 mil Profissionais da Escrita - entre escritores, redatores técnicos, críticos literários -, configurando razões de 19 e 9 profissionais por 100 mil habitantes, respectivamente. A família de Arquivistas e Museólogos compreendia um contingente de ocupados significativamente menor, de 1.067 pessoas em 2000.

Como era de se esperar, seja pelo porte, seja pela estrutura produtiva mais avançada de suas economias, os estados do Sudeste e Sul, além do Distrito Federal, concentravam a maior parte desses profissionais. O estado de São Paulo, sozinho, concentrava em 2000 um terço dos Profissionais do Jornalismo e outro tanto de Profissionais da Escrita, bem acima da participação de sua população no conjunto do país (22\%). Os Profissionais da Informação estavam distribuídos de forma menos concentrada pelos estados, chegando a totalizar parcelas significativas, não apenas no Centro-Sul, mas também em alguns estados do Norte, como em Roraima e Tocantins. O Distrito Federal, pelas características específicas de sede administrativa e centro político nacional, apresentava os maiores coeficientes de disponibilidade de profissionais por 100 mil habitantes: 78 jornalistas, 36 bibliotecários e 24 redatores técnicos para cada 100 mil habitantes, cifras bem acima da média nacional e dos próprios estados do Sudeste e Sul. 
Tabela 3. Profissionais de Informação, Comunicação e Escrita segundo Unidades da Federação. Brasil, 2000.

\begin{tabular}{|c|c|c|c|c|c|c|c|c|}
\hline \multirow{2}{*}{$\begin{array}{l}\text { Unidades da } \\
\text { Federação }\end{array}$} & \multicolumn{4}{|c|}{ Total de indivíduos nos grupos ocupacionais } & \multicolumn{4}{|c|}{ Razão de profissionais por 100 mil habitantes } \\
\hline & $\begin{array}{c}\text { Profissionais } \\
\text { Jornalismo }\end{array}$ & $\begin{array}{l}\text { Profissionais } \\
\text { Informação }\end{array}$ & $\begin{array}{c}\text { Profissionais } \\
\text { Escrita }\end{array}$ & Total $^{*}$ & $\begin{array}{c}\text { Profissionais } \\
\text { Jornalismo }\end{array}$ & $\begin{array}{l}\text { Profissionais } \\
\text { Informação }\end{array}$ & $\begin{array}{c}\text { Profissionais } \\
\text { Escrita }\end{array}$ & Total $^{*}$ \\
\hline Rondônia & 168 & 284 & 46 & 498 & 12,2 & 20,6 & 3,3 & 36,1 \\
\hline Acre & 93 & 124 & 24 & 241 & 16,7 & 22,2 & 4,3 & 43,2 \\
\hline Amazonas & 288 & 381 & 114 & 794 & 10,2 & 13,5 & 4,1 & 28,2 \\
\hline Roraima & 79 & 291 & 17 & 387 & 24,4 & 89,7 & 5,2 & 119,3 \\
\hline Pará & 398 & 942 & 124 & 1.485 & 6,4 & 15,2 & 2,0 & 24,0 \\
\hline Amapá & 12 & 57 & 13 & 82 & 2,5 & 11,9 & 2,7 & 17,2 \\
\hline Tocantins & 75 & 475 & 36 & 586 & 6,5 & 41,1 & 3,1 & 50,6 \\
\hline Maranhão & 366 & 597 & 121 & 1.084 & 6,5 & 10,6 & 2,1 & 19,2 \\
\hline Piauí & 276 & 467 & 163 & 906 & 9,7 & 16,4 & 5,7 & 31,9 \\
\hline Ceará & 331 & 1.000 & 391 & 1.722 & 4,5 & 13,5 & 5,3 & 23,2 \\
\hline Rio Grande do Norte & 362 & 768 & 102 & 1.235 & 13,0 & 27,7 & 3,7 & 44,5 \\
\hline Paraíba & 458 & 711 & 152 & 1.321 & 13,3 & 20,6 & 4,4 & 38,4 \\
\hline Pernambuco & 651 & 1.364 & 282 & 2.353 & 8,2 & 17,2 & 3,6 & 29,7 \\
\hline Alagoas & 264 & 219 & 148 & 638 & 9,4 & 7,8 & 5,2 & 22,6 \\
\hline Sergipe & 332 & 228 & 122 & 682 & 18,6 & 12,8 & 6,8 & 38,2 \\
\hline Bahia & 874 & 2.043 & 415 & 3.435 & 6,7 & 15,6 & 3,2 & 26,3 \\
\hline Minas Gerais & 2.818 & 3.961 & 1.099 & 7.927 & 15,8 & 22,1 & 6,1 & 44,3 \\
\hline Espírito Santo & 512 & 530 & 201 & 1.266 & 16,5 & 17,1 & 6,5 & 40,9 \\
\hline Rio de Janeiro & 5.281 & 3.297 & 2.342 & 11.255 & 36,7 & 22,9 & 16,3 & 78,2 \\
\hline São Paulo & 11.946 & 6.102 & 5.972 & 24.196 & 32,3 & 16,5 & 16,1 & 65,3 \\
\hline Paraná & 2.095 & 2.545 & 796 & 5.510 & 21,9 & 26,6 & 8,3 & 57,6 \\
\hline Santa Catarina & 1.225 & 1.494 & 561 & 3.332 & 22,9 & 27,9 & 10,5 & 62,2 \\
\hline Rio Grande do Sul & 1.892 & 2.216 & 1.142 & 5.318 & 18,6 & 21,8 & 11,2 & 52,2 \\
\hline Mato Grosso do Sul & 340 & 388 & 173 & 910 & 16,4 & 18,7 & 8,3 & 43,8 \\
\hline Mato Grosso & 338 & 392 & 177 & 907 & 13,5 & 15,7 & 7,1 & 36,2 \\
\hline Goiás & 669 & 909 & 283 & 1.887 & 13,4 & 18,2 & 5,7 & 37,7 \\
\hline Distrito Federal & 1.606 & 742 & 495 & 2.889 & 78,3 & 36,2 & 24,1 & 140,8 \\
\hline Brasil & 33.749 & 32.527 & 15.511 & 82.846 & 19,9 & 19,2 & 9,1 & 48,8 \\
\hline
\end{tabular}

Fonte: Censo Demográfico (2000).

Nota: $\left(^{*}\right)$ Total inclui indivíduos ocupados na família ocupacional 2613 (Museólogos e afins), que totalizam 1067 profissionais no país.

\section{Indicadores de oferta de serviços bibliotecários nos Estados}

Se se puder comparar os resultados da já citada Pesquisa Bibliotecas Brasileiras, referida a 1976, com os dados da MUNIC de 1999, no que diz respeito à quantidade de bibliotecas públicas houve um avanço significativo da oferta de equipamentos no conjunto do país. Em 1976 havia 3.257 bibliotecas públicas - com acervo de 300 ou mais volumes - e, em 1999, havia 5.514 unidades, um total $70,0 \%$ maior (Tabela $4)^{13}$. Em 23 anos, houve um acréscimo de quase 100 bibliotecas por ano ou, de forma equivalente, um crescimento médio anual de $2,3 \%$, cifra significativamente superior ao crescimento

\footnotetext{
${ }^{13}$ Vale observar que a MUNIC de 1999 investigou não apenas a existência de biblioteca pública, como também o número de unidades de informação.
} 
populacional no período ( $1,8 \%$ ao ano entre 1980 e 2000).

Essa ampliação da oferta de equipamentos deve ser analisada com cautela, já que a contabilização de bibliotecas públicas instaladas fornece um indicador muito limitado da disponibilidade de serviços bibliotecários no país, não permitindo a inferência direta acerca do aumento, per capita, do espaço físico das bibliotecas ou do volume e diversidade de livros colocados à disposição do público. Afinal, um coeficiente de oferta de 3,2 bibliotecas públicas por 100 mil pessoas apurado para o Brasil em 2000 é até bastante razoável comparado com o

Tabela 4. Profissionais de Informação, Bibliotecas e indicadores de disponibilidade de serviços bibliotecários segundo Unidades da Federação. Brasil, 1999-2000.

\begin{tabular}{|c|c|c|c|c|c|}
\hline \multirow[b]{2}{*}{$\begin{array}{l}\text { Unidades da } \\
\text { Federação }\end{array}$} & \multicolumn{2}{|c|}{ Totais } & \multicolumn{3}{|c|}{ Indicadores de recursos } \\
\hline & $\begin{array}{l}\text { Profissionais } \\
\text { Informação }\end{array}$ & $\begin{array}{l}\text { Bibliotecas } \\
\text { Públicas }\end{array}$ & $\begin{array}{l}\text { Profissionais da } \\
\text { Informação por } \\
100.000 \text { hab. }\end{array}$ & $\begin{array}{l}\text { Bibliotecas Públicas } \\
\text { por } 100.000 \text { hab. }\end{array}$ & $\begin{array}{c}\text { Municípios com } \\
\text { pelo menos } 1 \\
\text { Biblioteca }(\%)\end{array}$ \\
\hline Rondônia & 284 & 35 & 20,6 & 2,5 & 65,3 \\
\hline Acre & 124 & 12 & 22,2 & 2,2 & 45,4 \\
\hline Amazonas & 381 & 47 & 13,5 & 1,7 & 70,9 \\
\hline Roraima & 291 & 6 & 89,7 & 1,8 & 33,3 \\
\hline Pará & 942 & 140 & 15,2 & 2,3 & 76,2 \\
\hline Amapá & 57 & 8 & 11,9 & 1,7 & 50,0 \\
\hline Tocantins & 475 & 161 & 41,1 & 13,9 & 79,8 \\
\hline Maranhão & 597 & 126 & 10,6 & 2,2 & 52,0 \\
\hline Piauí & 467 & 122 & 16,4 & 4,3 & 44,7 \\
\hline Ceará & 1.000 & 190 & 13,5 & 2,6 & 82,0 \\
\hline Rio Grande do Norte & 768 & 163 & 27,7 & 5,9 & 90,9 \\
\hline Paraíba & 711 & 180 & 20,6 & 5,2 & 66,3 \\
\hline Pernambuco & 1.364 & 207 & 17,2 & 2,6 & 85,4 \\
\hline Alagoas & 219 & 71 & 7,8 & 2,5 & 64,3 \\
\hline Sergipe & 228 & 52 & 12,8 & 2,9 & 61,3 \\
\hline Bahia & 2.043 & 353 & 15,6 & 2,7 & 67,9 \\
\hline Minas Gerais & 3.961 & 901 & 22,1 & 5,0 & 83,0 \\
\hline Espírito Santo & 530 & 85 & 17,1 & 2,7 & 92,2 \\
\hline Rio de Janeiro & 3.297 & 178 & 22,9 & 1,2 & 84,6 \\
\hline São Paulo & 6.102 & 822 & 16,5 & 2,2 & 82,4 \\
\hline Paraná & 2.545 & 435 & 26,6 & 4,5 & 81,4 \\
\hline Santa Catarina & 1.494 & 345 & 27,9 & 6,4 & 79,8 \\
\hline Rio Grande do Sul & 2.216 & 426 & 21,8 & 4,2 & 78,3 \\
\hline Mato Grosso do Sul & 388 & 93 & 18,7 & 4,5 & 89,6 \\
\hline Mato Grosso & 392 & 119 & 15,7 & 4,8 & 75,3 \\
\hline Goiás & 909 & 224 & 18,2 & 4,5 & 77,6 \\
\hline Distrito Federal & 742 & 13 & 36,2 & 0,6 & 100,0 \\
\hline Brasil & 32.527 & 5.514 & 19,2 & 3,2 & 76,3 \\
\hline
\end{tabular}

Fonte: Censo Demográfico (2000). 
da França, de 4,4 bibliotecas por 100 mil. Mas seriam comparáveis - em tamanho do acervo, diversidade cultural, equipamentos e facilidades disponíveis - as bibliotecas francesas e as brasileiras? Talvez a comparação com o México seja mais apropriada e, nesse caso, o quadro de oferta brasileiro fica bem aquém, já que lá o coeficiente era de cerca de 5 bibliotecas por 100 mil pessoas no final dos anos 1990, segundo estatísticas compiladas pela Unesco ${ }^{14}$. O fato é que, em termos comparativos internacionais, a oferta de serviços bibliotecários no Brasil ainda fica aquém da existente em outros países, para os quais se pode arriscar um cotejamento estatístico responsável ${ }^{15}$.

Essas ressalvas metodológicas também se aplicam na análise do indicador de disponibilidade de bibliotecas públicas por $100 \mathrm{mil}$ habitantes pelos estados. Afinal, seria correto inferir, de forma simples e direta, que a oferta de serviços bibliotecários à população em Tocantins (14 unidades por 100 mil pessoas) é mais de 10 vezes superior que a apurada para o Estado do Rio de Janeiro (1,2 unidade por 100 mil pessoas)? Certamente que não, embora haja algo de muito diferente acontecendo em Tocantins, e que mereceria ser investigado. Seria uma política pública deliberada de implantação de bibliotecas públicas nos municípios do Estado? Seria uma forma de compensar a oferta restrita de venda de livros no estado? Seria um enviesamento da coleta de dados?

Por outro lado, os dados relativos ao Rio de Janeiro conduzem a outros questionamentos: estariam as cidades médias, da Baixada Fluminense e do interior do estado, com unidades de prestação de serviços bibliotecários em nível compatível com a demanda em potencial?
Estaria a população da capital adequadamente atendida? Estariam os dados da pesquisa mais fidedignos nesse estado, onde a supervisão técnica poderia ser-em tese-mais abrangente, já que nele se situa o IBGE? De qualquer forma, indicadores servem para apontar tendências, diferenciais, identificar casos destoantes e, se usados com bom senso e dentro de suas limitações, permitem aprofundar a investigação social (JANNUZZI, 2001) ${ }^{16}$.

Uma outra estratégia para analisar a disponibilidade de oferta de serviços bibliotecários nos estados brasileiros é através do contingente de Bibliotecários, Biblioteconomistas e outros ocupados na categoria Profissionais da Informação, balizado pelo total populacional. Como já apontado anteriormente, pelo Censo Demográfico 2000 , havia 32.527 mil pessoas ocupadas que declararam desempenhar atividades dentre as que a CBO 2002 classifica como as típicas de Profissionais da Informação. É um contigente expressivamente maior que o quantitativo levantado no Censo Demográfico de 1991, de 19.030 bibliotecários (CENSO..., 1991).

Ainda que se deva ter cuidado adicional com a comparação de efetivos de categorias ocupacionais entre os Censos, tendo em vista as mudanças dos sistemas de classificação de ocupações no período, esse resultado parece revelar uma tendência bem mais virtuosa de crescimento de postos de trabalho de biblioteconomistas no país que a descrita em trabalho anterior (JANNUZZI; MATTOS, 2001).

Neste trabalho, tendo em vista outros objetivos analíticos, optou-se por selecionar os ocupados com 15 a 64 anos, com 38 ou mais horas no trabalho principal, com rendimento e escolaridade declarados nas pesquisas, o que

\footnotetext{
14 Segundo informações disponíveis em www.uis.unesco.org, a França tinha 2.577 bibliotecas e 12.864 empregados nas mesmas (entre os com nível superior e técnico) em 1997; o México, 5.313 bibliotecas e 12.008 empregados.

${ }^{15}$ As comparações internacionais de indicadores - especialmente os sociais - devem ser vistas com ressalvas adicionais, em função das inevitáveis diferenças de conceitos e categorias empregadas por cada país, mesmo quando as informações são compiladas pelos organismos internacionais como a Unesco.

${ }^{16}$ Além disso, somente com o uso dos indicadores para fins analíticos que se pode ajudar a melhorar a qual idade efidedignidade dos dados levantados em campo.
} 
acabou excluindo contigente expressivo de trabalhadores na área, em regime de trabalho em tempo parcial ou tempo corrido de 6 horas diárias ${ }^{17}$. De fato, naquele trabalho, o total apontado de biblioteconomistas em 1991 era de 11.217 pessoas, apontando uma relação de 59\% de ocupados com jornada superior a 38 horas semanais (e portanto $41 \%$ em tempo parcial). Aplicando os critérios acima nos dados do Censo 2000, chega-se a 17.857 pessoas, significando um aumento da parcela de ocupados em tempo parcial $(45 \%)^{18}$.

Se puder usar-se dos dados fornecidos pela Unesco em bases comparativas internacionais, a disponibilidade de Profissionais da Informação no Brasil estaria próxima da existente na França (19,2 profissionais por 100 mil habitantes no Brasil e 22,2 na França), e superior a do México (12 profissionais por 100 mil). Pelo que sugerem os dados, as bibliotecas no México utilizam menos pessoal que no Brasil, já que como apresentado anteriormente, a quantidade de bibliotecas disponíveis naquele país é superior.

Em termos comparativos estaduais, como já descrito na seção anterior, a disponibilidade de Profissionais da Informação para atendimento à população é mais elevada no Distrito Federal, e sobretudo em Roraima e Tocantins ${ }^{19}$. Vale observar que, Paraná, Santa Catarina e Rio Grande do Norte, apresentaram indicadores de disponibilidade de pessoal significativamente maiores que a média nacional. Por outro lado, São Paulo apresenta cifra de disponibilidade mais baixa que a média, de 16,5 profissionais por 100 mil habitantes.

O cotejamento de indicadores de disponibilidade de serviços - bibliotecas ou profissionais de informação por mil habitantes - com indicadores sociais e econômicos dos estados

Tabela 5. Coeficientes de Correlação de Pearson e Spearman entre indicadores de disponibilidade e indicadores sociais e econômicos dos estados.

\begin{tabular}{lccccc}
\hline Indicador social, econômico ou de Disponibilidade & $\begin{array}{c}\text { Profissionais da } \\
\text { Informação por 100.000 hab. }\end{array}$ & & \multicolumn{2}{c}{$\begin{array}{c}\text { Bibliotecas Públicas } \\
\text { por } 100.000 \text { hab. }\end{array}$} \\
\cline { 5 - 6 } \cline { 5 - 6 } de serviços & Pearson & Spearman & & Pearson Spearman \\
\hline Prop. Pessoas de 10 anos ou mais com até 3 anos estudo & $-0,30$ & $-0,44^{*}$ & & 0,13 & 0,18 \\
Despesas estaduais per capita com educação e cultura & 0,60 & $0,50^{* *}$ & & $-0,06$ & $-0,14$ \\
Produto Interno Bruto per capita & $-0,01$ & $-0,29$ & & $-0,18$ & $-0,11$ \\
Profissionais Informação por 100.000 hab & 1,00 & 1,00 & & 0,16 & 0,26 \\
Biblioteca Pública por 100.000 hab & 0,16 & 0,26 & & 1,00 & 1,00 \\
\hline
\end{tabular}

Nota: $\left(^{*}\right)=$ associação significante a $5 \%$.

$\left(^{* *}\right)=$ associação significante a $1 \%$.

17 Como era um estudo comparativo da evolução quantitativa e da qualidade de inserção ocupacional de quatro categorias profissionais foi necessário compatibilizar a jornada de trabalho, sem o que, indicadores com o rendimento médio, por exemplo, não poderiam ser cotejados.

${ }^{18}$ Vale observar que o termo "Profissionais da Informação", usado em trabalho anterior (JAN NUZZI e MATTOS, 2001), designava um contingente maior de ocupações e profissões, incluindo aquelas que, de al guma forma, lidavam com a coleta, armazenamento, tratamento, análise e disseminação da informação. Incluía, pois, analistas de sistemas, estatísticos, professores, economistas, além de bibliotecários, arquivistas e jornalistas. Não é pois uma categoria comparável com a usada pela CBO 2002. Assim, novos estudos sobre Formação Profissional e Mercado de Trabalho desenvolvidos na Ciência da Informação deveriam evitar o uso do termo sem que se referissem à categoria normativa agora instituída.

190 caso de Tocantins, como já apontado com base em outro indicador e outra fonte de dados, confirma a singularidade do quadro de oferta de serviços bibliotecários no estado. 
brasileiros, não corrobora a percepção advinda da análise descritiva, anteriormente apresentada, de que não haveria um padrão claro de correlação entre tais dimensões - pelo menos do ponto de vista de significância estatística. São baixos, em geral, os coeficientes de correlação - linear e ordinal - entre os indicadores. Uma exceção é a associação positiva - e significante a $1 \%$ - entre a razão de profissionais por 100 mil pessoas e o gasto estadual per capita em educação e saúde (Tabela 5). Vale notar também que, tampouco, observou-se associação significativa entre os dois indicadores de serviços - bibliotecas e profissionais da informação por 100 mil habitantes, isto é, uma oferta maior de bibliotecas não significa necessariamente maior disponibilidade de profissionais da informação trabalhando no estado.

Tais resultados apontam que, embora seja mais comum que estados mais pobres tenham indicadores de disponibilidade de serviços bibliotecários mais baixos, o fato é que, como visto, mesmo entre esses estados, com maior parcela de população de baixa escolaridade ou menor despesa estadual com educação e cultura, há aqueles com indicadores razoáveis de oferta de serviços. Da mesma forma, também podem encontrar-se estados mais ricos, com indicadores de disponibilidade abaixo da média nacional. Tocantins e o Rio de Janeiro são dois exemplos emblemáticos, em um caso e no outro. Ou seja, o nível da oferta de serviços bibliotecários públicos não depende - somente - de maior disponibilidade de recursos na economia ou no orçamento estadual. Também podem ser importantes iniciativas locais, da sociedade civil ou mesmo programas gestados nos governos estaduais, por vontade política e persistência de alguns grupos de "militantes da leitura e do livro", em geral nas secretarias estaduais de Educação.

Se não há clara associação estatística entre os indicadores econômicos, sociais e de disponibilidade de serviços bibliotecários é
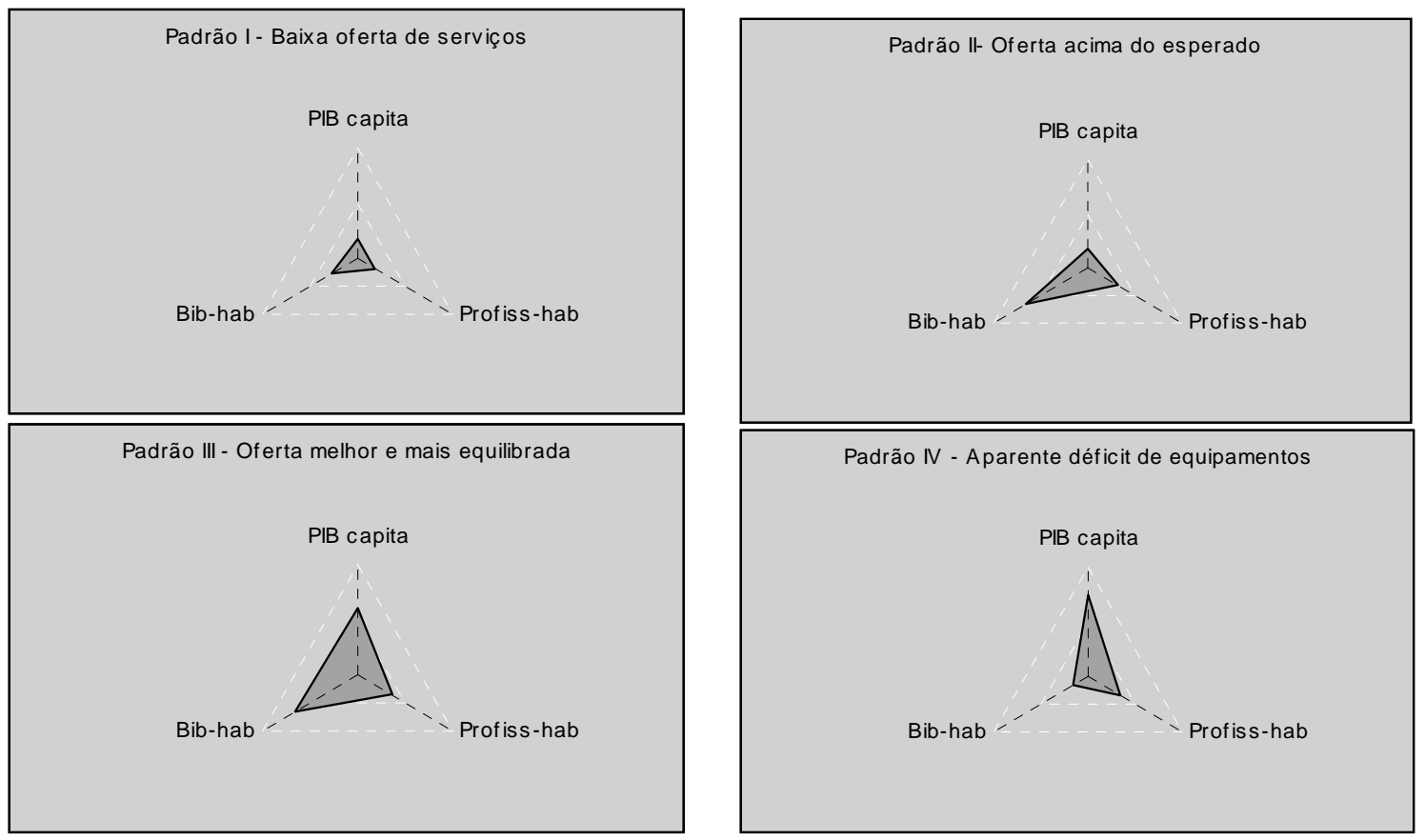

Figura 1. Padrões de oferta de serviços bibliotecários pelos estados. 
possível buscar, através de análise de aglomerados (cluster analysis), a identificação de padrões estaduais de disponibilidade de serviços, tendo como base os diferentes níveis de desenvolvimento econômico. A partir da combinação de indicadores de recursos econômicos (PIB, por exemplo) e indicadores de oferta de serviços pode-se identificar as boas práticas de políticas ou casos exemplares para estudo específico.

Assim, como mostram a Figura 1 e a Tabela 6 , há quatro situações mais gerais de oferta de serviços pelos estados: I) baixa oferta, decorrente de menor disponibilidade de recursos econômicos (PIB per capita), situação típica do Maranhão e Sergipe; II) padrão de oferta acima do esperado frente aos baixos recursos disponíveis, como Rio Grande do Norte; III) situação de melhor disponibilidade de infra-estrutura, como no Rio Grande do Sul e Mato Grosso do Sul; IV) oferta aquém do esperado pela disponibilidade de recursos, situação dos estados mais populosos como Rio de Janeiro e São Paulo.

\section{CONSIDERAÇÕ ES FIN A IS}

Pelas fontes de dados aqui consultadas, constatou-se que, embora a biblioteca pública ainda não seja uma realidade para a totalidade dos municípios brasileiros, ela é o equipamento cultural mais disseminado pelo território, presente em $76 \%$ dos municípios no país. Museus e teatros são equipamentos mais escassos, principalmente se comparados com outros estudados como as próprias bibliotecas públicas, livrarias e vídeo locadoras. Entende-se que as políticas de apoio à cultura, por parte dos governos federal, estadual e municipal, devem melhorar as contribuições e incentivos financeiros para a expansão e reavivamento deste tipo de equipamento cultural. Informação e cultura são assimiladas pela população de várias formas e é importante que os canais disseminadores, isto é, os equipamentos culturais disponíveis sejam variados. Dessa maneira enriquecerão o conjunto de informações ao público.

A abrangência limitada na captação de sinal de TVs Educativas é um ponto que merece

Tabela 6. Indicadores dos grupos de estados classificados segundo padrões de oferta de serviços bibliotecários.

\begin{tabular}{|c|c|c|c|c|}
\hline Padrão de oferta & UF componentes* & $\begin{array}{l}\text { Profissionais da } \\
\text { Informação por } \\
100.000 \text { hab. }\end{array}$ & $\begin{array}{l}\text { Bibliotecas } \\
\text { Públicas por } \\
100.000 \text { hab. }\end{array}$ & $\begin{array}{c}\text { PIB per } \\
\text { capita }(\mathrm{R} \$)\end{array}$ \\
\hline $\begin{array}{l}\text { - Baixa oferta de } \\
\text { serviços }\end{array}$ & $\begin{array}{l}\text { Rondônia, Acre, Pará, Amapá, } \\
\text { Maranhão, Ceará, Pernambuco, } \\
\text { Alagoas, Sergipe, Bahia }\end{array}$ & 14,7 & 2,4 & $3.181,00$ \\
\hline $\begin{array}{c}\| \text { - Oferta acima do } \\
\text { esperado }\end{array}$ & $\begin{array}{l}\text { Piauí, Rio Grande do Norte, Paraíba, } \\
\text { Goiás }\end{array}$ & 20,7 & 5,0 & $3.053,50$ \\
\hline $\begin{array}{l}\text { III - Oferta melhor e mais } \\
\text { equilibrada }\end{array}$ & $\begin{array}{l}\text { Minas Gerais, Paraná, Santa } \\
\text { Catarina, Rio Grande do Sul, Mato } \\
\text { Grosso do Sul, Mato Grosso }\end{array}$ & 22,1 & 4,9 & $6.681,50$ \\
\hline $\begin{array}{l}\text { IV - Aparente déficit de } \\
\text { equipamentos físicos }\end{array}$ & $\begin{array}{l}\text { Amazonas, Espírito Santo } \\
\text { Rio de Janeiro, São Paulo } \\
\text { Distrito Federal }\end{array}$ & 21,2 & 1,7 & $7.927,60$ \\
\hline Média Nacional & - & 19,2 & 3,2 & $6.377,25$ \\
\hline
\end{tabular}

Nota: $\left(^{*}\right)$ Excluídos os estados de Roraima e Tocantins que têm padrões muito específicos de oferta. 
maior atenção das autoridades governamentais, tanto para melhor inserção deste tipo de equipamento nos municípios brasileiros, quanto para despertar o interesse de maior parcela de espectadores às programações desse tipo de TV.

Em relação aos trabalhadores da difusão cultural, grupo formado pelos Profissionais da Informação, do Jornalismo, da Escrita, Arquivistas e Museólogos, este trabalho pode apontar que a CBO 2002 trouxe melhorias quanto à seleção e classificação dos profissionais em relação às suas ocupações. Vale destacar que esses profissionais têm um nível de estudo considerado alto, em relação à população total do país, e, esse fator interfere na sua maior distribuição pelos estados de economias mais avançadas como os do Sudeste e Sul e no Distrito Federal.

Assim, muito antes de se pensar em políticas de universalização do acesso à informação digital, é preciso superar as restrições de acesso a fontes informacionais e equipamentos culturais básicos (e "pré-modernistas") a que boa parcela da população brasileira está sujeita. Não se trata de negar a importância do acesso digital. Mas, antes de garantir apenas o acesso digital, é preciso conseguir ampliar a apropriação intelectual da informação e cultura, e formar cidadãos, pessoas com capacidade crítica, com a possibilidade de escolher conteúdos, de posicionar-se politicamente. É preciso que os excluídos - digitais, informacionais e culturais - sejam inseridos por meio de ações educacionais e culturais mais amplas, na escola e fora dela, garantindo-Ihes acesso à informação plural, veiculada nas bibliotecas, livrarias, teatros, TVs educativas, cinemas e outros tantos meios.

Ao se debruçar sobre a disponibilidade de equipamentos físicos e recursos humanos, alocados na disseminação de informação, comunicação e divulgação cultural no Brasil, este trabalho procura contribuir em dois campos complementares. No campo acadêmico trouxe evidências empíricas importantes e de certa forma inéditas - até onde se pôde verificar - sobre a acessibilidade da sociedade a repertórios plurais de informação, em suportes convencionais tais como a biblioteca pública, a livraria e os jornais. No campo das políticas públicas, o trabalho apresenta um diagnóstico preliminar para formulação de programas públicos na área, ampliando o escopo dos projetos então idealizados, centrados hoje, basicamente, na ampliação de acesso aos suportes digitais como a Internet (como o da Sociedade da Informação já citado e o que parece estar nos planos do Ministério das Comunicações, com recursos do Fundo Público de Serviços de Telecomunicações).

Naturalmente, tal diagnóstico é apenas mais uma peça na montagem de um grande quebra-cabeça, seja na pesquisa em Ciência da Informação, seja na Formulação de Políticas em Ação Cultural e Cidadania. Há muito por se fazer, por exemplo, no sentido de se conhecer o acervo disponibilizado ao público nas bibliotecas (Literatura infantil, Anuários Estatísticos, Mapas, Enciclopédias, Clássicos da Literatura Nacional e Estrangeira, Jornais, Revistas etc.), nos museus ou mesmo na programação e uso dos teatros. Enquanto grandes ações e políticas públicas não acontecem na área, talvez se pudesse fazer algo de pontual, mas concreto, aproveitando a existência de uma rede capilarizada de bibliotecas públicas no país, cobrindo três quartos dos municípios brasileiros, como a distribuição de coleções de livros infantis, conjunto de atlas e anuários estatísticos, distribuição de estantes, exposições de artesanatos regionais, instalação de, ao menos um microcomputador com Internet.

Para potencializar os resultados na área seria importante rever práticas e orientações muito arraigadas, superando a concepção operacional jesuítica da biblioteca pública brasileira, e abraçando o ideal de biblioteca pública em uma perspectiva mais pós-moderna, 
entendendo-a como centro de distribuição, consumo e produção de produtos culturais ou, nos termos de Teixeira Coelho (1997), transformando-a em uma Máquina Cultural. Ações efetivas nesse sentido, de possibilitar o

\section{REFERÊ N CIAS}

ALKMIN, A.C. A economia da cultura no Rio de Janeiro. Rio de Janeiro, 2002. Mimeografado.

BAGGIO, R. A sociedade da informação e a infoexclusão. Ciência da Informação, Brasília, v.29, n.2, p.16-21, 2000.

CÂMARA BRASILEIRA DO LIVRO. Retrato da leitura no Brasil. São Paulo, 2001. 1 CD-ROM.

CARVALHO, I.C.L.; KANISKI, A.L. A sociedade do conhecimento e o acesso à informação: para que e para quem? Ciência da Informação, Brasília, v.29, n.3, p.33-39, 2000.

CENSO DEMOGRÁFICO 1991. Rio de Janeiro: IBGE, 1991. Disponível em: <http://www.sibra. ibge.gov.br/bda>. Acesso em: 7 jan. 2004.

CENSO DEMOGRÁFICO 2000. Rio de Janeiro: IBGE, 2000. Disponível em: <http://www.ibge.gov.br/ censo/default.php>. Acesso em: 7 jan. 2004.

CIRCULAÇÃO DIÁRIA MÉDIA DOS PRINCIPAIS JORNAIS DO MUNDO. Folha de São Paulo, São Paulo, 18 fev. 2001. Caderno Especial, p.31. CLASSIFICAÇÃO BRASILEIRA DE OCUPAÇÕES 2002. Brasília: MTb, 2002. Disponível em: <http:// www.mtecbo.gov.br/>. Acesso em: 7 jan. 2004.

CUNHA, M.B. Construindo o futuro: a biblioteca universitária brasileira em 2010. Ciência da Informação, Brasília, v.29, n.1, p.71-89, 2000.

GERMAN, C. O caminho do Brasil rumo à era da informação. São Paulo: Adenauer, 2000. $127 p$. acesso cultural, em sentido amplo, à população, são condições necessárias - ainda que não suficientes - para ingresso virtuoso - e não apenas virtual - na Sociedade da Informação e do Conhecimento.

JANNUZZI, P.M. Indicadores sociais no Brasil: conceitos, fonte de dados e aplicações. Campinas: Alínea, 2001. 141p.

JANNUZZI, P.M.; MATTOS, F.A.M. Duas décadas de conjuntura econômica: de (des)emprego industrial e de inserção dos profissionais da informação no mercado de trabalho. Transinformação, Campinas, v.13, n.2, p.123-143, 2001.

PESQUISA BIBLIOTECAS BRASILEIRAS. Rio de Janeiro: IBGE, 1980. 75p.

PESQUISA DE CONDIÇÕES DE VIDA 1998: primeiros resultados. São Paulo: SEADE, 1998. $110 p$.

PESQUISA DE INFORMAÇÕES BÁSICAS MUNICIPAIS. Rio de Janeiro: IBGE, 2001. 1 CD-ROM.

ROCHA, M.P.C. A questão cidadania na sociedade da informação. Ciência da Informação, Brasília, v.29, n.1, p.40-45, 2000.

SCHWARTZ, G. As profissões do futuro. São Paulo: Publifolha, 2000. 106p. (Folha explica; 11).

SICILIANO, O. No combate à fome do livro. Folha de São Paulo, São Paulo, 23 abr. 2003. Brasil, Opinião, p.A-3.

SUAIDEN, E. J. A biblioteca pública no contexto da sociedade da informação. Ciência da Informação, Brasília, v.29, n.2, p.52-60, 2000.

TAKAHASHI, T. (Org.). Sociedade da informação no Brasil: livro verde. Brasília: Ministério da Ciência e Tecnologia, 2000. 195p.

TEIXEIRA COELHO, J. Dicionário Crítico de Política Cultural. São Paulo: [s.n.], 1997. p.33-169. 


\section{APÊNDICE}

Indicadores demográficos, sociais e econômicos das Unidades da Federação. Brasil, 2000.

\begin{tabular}{|c|c|c|c|c|c|}
\hline $\begin{array}{l}\text { Unidades da } \\
\text { Federação }\end{array}$ & $\begin{array}{l}\text { Número de } \\
\text { Munícipios* }\end{array}$ & $\begin{array}{l}\text { População } \\
\text { residente }\end{array}$ & $\begin{array}{c}\text { Prop. Pessoas } \\
\text { de } 10 \text { anos ou mais } \\
\text { com até } 3 \text { anos } \\
\text { estudo }(\%)\end{array}$ & $\begin{array}{c}\text { Despesas } \\
\text { estaduais per capita } \\
\text { com educação e } \\
\text { cultura }(R \$)\end{array}$ & $\begin{array}{c}\text { Produto } \\
\text { Interno Bruto } \\
\text { per capita }(\mathrm{R} \$)\end{array}$ \\
\hline Rondônia & 52 & 1.379 .787 & 36,7 & 164,00 & 4.065 \\
\hline Acre & 22 & 557.526 & 46,2 & 328,89 & 3.037 \\
\hline Amazonas & 62 & 2.812 .557 & 36,1 & 161,51 & 6.668 \\
\hline Roraima & 15 & 324.397 & 29,4 & 402,21 & 3.417 \\
\hline Pará & 143 & 6.192 .307 & 41,2 & 86,08 & 3.041 \\
\hline Amapá & 16 & 477.032 & 28,4 & 322,33 & 4.098 \\
\hline Tocantins & 139 & 1.157 .098 & 40,5 & 203,08 & 2.110 \\
\hline Maranhão & 217 & 5.651 .475 & 53,2 & 53,29 & 1.627 \\
\hline Piauí & 221 & 2.843 .278 & 56,6 & 92,92 & 1.874 \\
\hline Ceará & 184 & 7.430 .661 & 44,3 & 102,76 & 2.794 \\
\hline Rio Grande do Norte & 166 & 2.776 .782 & 44,8 & 169,85 & 3.343 \\
\hline Paraíba & 223 & 3.443 .825 & 50,5 & 133,36 & 2.681 \\
\hline Pernambuco & 185 & 7.918 .344 & 40,3 & 52,26 & 3.673 \\
\hline Alagoas & 101 & 2.822 .621 & 49,9 & 92,46 & 2.485 \\
\hline Sergipe & 75 & 1.784 .475 & 45,2 & 148,30 & 3.310 \\
\hline Bahia & 415 & 13.070 .250 & 46,7 & 100,91 & 3.680 \\
\hline Minas Gerais & 853 & 17.891 .494 & 30,8 & 185,80 & 5.925 \\
\hline Espírito Santo & 77 & 3.097 .232 & 32,4 & 97,41 & 6.931 \\
\hline Rio de Janeiro & 91 & 14.391 .282 & 20,9 & 258,67 & 9.571 \\
\hline São Paulo & 645 & 37.032 .403 & 20,2 & 206,45 & 9.995 \\
\hline Paraná & 399 & 9.563 .458 & 26,8 & 141,91 & 6.882 \\
\hline Santa Catarina & 293 & 5.356 .360 & 23,3 & 150,06 & 7.902 \\
\hline Rio Grande do Sul & 467 & 10.187 .798 & 22,3 & 197,19 & 8.341 \\
\hline Mato Grosso do Sul & 77 & 2.078 .001 & 34,9 & 160,21 & 5.697 \\
\hline Mato Grosso & 126 & 2.504 .353 & 32,7 & 187,04 & 5.342 \\
\hline Goiás & 242 & 5.003 .228 & 28,8 & 119,17 & 4.316 \\
\hline Distrito Federal & 1 & 2.051 .146 & 16,1 & 471,19 & 6.473 \\
\hline Total & 5507 & 169.799 .170 & 31,4 & 164,68 & 6.377 \\
\hline
\end{tabular}

Fonte: Pesquisa... (2001), Censo Demográfico... (2000), Contas Regionais 1997-2000. Nota: $\left({ }^{*}\right)$ Dados referentes a 1999. 